\title{
UN TRONO CONSTITUCIONAL PARA FRANCIA: CHATEAUBRIAND Y LA IDEA DE UNA MONARQUÍA LIBERAL
}

\author{
A CONSTITUTIONAL THRONE FOR FRANCE: CHATEAUBRIAND AND \\ THE IDEA OF A LIBERAL MONARCHY
}

\author{
Armando Zerolo Durán* \\ Universidad San Pablo-CEU, Madrid-España
}

\begin{abstract}
RESUMEN: En este artículo estudiamos la participación de Chateaubriand en el periódico $E l$ Conservador con el fin de destacar el alcance que tuvo su papel en la interpretación, explicación y diseño del sistema constitucional establecido en la Carta constitucional otorgada por Luis XVIII en 1814. La originalidad de la investigación reside en situar el centro de atención en el pensamiento que emanó del confrontamiento implícito entre Chateaubriand y el partido ultra, y no en el enfoque más común que se ha centrado siempre en las discusiones explícitas entre el tribuno conservador y sus adversarios liberales. La particularidad de las ideas que se destilan de esta fuente reside en que, mientras otros destacados políticos actuaban desde una tribuna que les era afín, como fue el caso de Benjamin Constant y el diario La Minerve, Chateaubriand lo hizo desde un diario, El Conservador, con el que no compartía todas las opiniones. Su misión durante la Restauración fue predicar el constitucionalismo entre los devotos del absolutismo.
\end{abstract}

PALABRAS CLAVE: Monarquía constitucional, Liberalismo, Conservadurismo, División de poderes, Restauración, Representación.

ABSTRACT: In this article we study Chateaubriand's participation in the newspaper Le Conservateur in order to highlight the extent of his role in the interpretation, explanation and design of the constitutional system established in the constitutional charter granted by Louis XVIII in 1814. The originality of the research lies in placing the focus on the thought that emanated from the implicit confrontation between Chateaubriand and the ultra party, and not on the more common approach that has always focused on the explicit discussions between the conservative tribune and his liberal adversaries. The particularity of the ideas that are distilled from this source lies in the fact that, while other prominent politicians acted from a tribune that was similar to them, as was the case with Benjamin Constant and the newspaper La Minerve, Chateaubriand did so from a newspaper, Le Conservateur, with which he did not share all the opinions. His mission during the Restoration was to preach constitutionalism among the devotees of absolutism.

KEYWORDS: Constitutional Monarchy, Liberalism, Conservation, Division of power, Restauration, Representation.

* Correspondencia a / Corresponding author: Armando Zerolo Durán. Universidad CEU San Pablo. Campus de Moncloa. Calle Julián Romea, 23 (28003 Madrid). -azduran@ceu.es - https://orcid.org/0000-0002-4306-8457

Cómo citar / How to cite: Zerolo Durán, Armando (2021). "Un trono constitucional para Francia: Chateaubriand y la idea de una monarquía liberal», Historia Contemporánea, 67, 867-896. (https://doi.org/10.1387/hc.21466).

Recibido/Received: 2020-01-21; Aceptado/Accepted: 2020-06-08.

ISSN 1130-2402 - eISSN 2340-0277 / (C) 2021 Historia Contemporánea (UPV/EHU)

(c) (i) $€$ Esta obra está bajo una Licencia

(cc) Creative Commons Atribución-NoComercial-SinDerivadas 4.0 Internacional 
¿Qué es la Monarquía Constitucional? «Es la transición natural entre las antiguas ideas y las nuevas, el punto de encuentro entre la monarquía y la república.» 1

\section{Introducción}

El pensamiento político de Chateaubriand y su concepción de la monarquía constitucional son conocidos ${ }^{2}$, pero aún hoy recae sobre él el estigma de que fue un defensor del Antiguo Régimen y un adversario de las propuestas constitucionales moderadas. La realidad es que este juicio no hace justicia con el verdadero pensamiento de Chateaubriand y que para conocerlo con exactitud es preciso contrastarlo con los hechos. El periódico El Conservador nos ofrece una fuente histórica importante y poco explorada para comprender la originalidad de la propuesta del autor de La monarquía según la Carta. A pesar de que la mayoría de los historiadores de las ideas suelen presentar a Chateaubriand como un adversario de los liberales, lo cual en parte es cierto, nosotros pretendemos mostrar que el verdadero interés de su propuesta se aprecia en la lucha que mantuvo con los miembros de su partido.

En las correcciones, advertencias, sugerencias y elocuentes silencios que mostró desde la tribuna del periódico ultra $^{3}$ vemos un pensamiento sumamente original, con unas propuestas modernas y constitucionales que intentaron adaptarse con sinceridad a las exigencias históricas de una monarquía liberal y posrevolucionaria.

\section{De la sociedad aristocrática a la sociedad burguesa}

La monarquía en Francia durante el periodo de la Restauración (18141830) fue la punta de lanza del constitucionalismo. El debate acerca de la

${ }^{1}$ Chateaubriand, François-René de. «Carta de Paris», El Conservador, 24 de agosto de 1823, disponible en Chateaubriand, 2013, p. 309.

2 Zerolo, 2017.

3 Tort explica que el origen del término «ultra», si bien tiene un origen despectivo que probablemente encuentre su origen en el ministro de la policía, Joseph Fouché, «entre 1816 y 1819 la expresión se generaliza y parece convertirse en meramente descriptiva bajo la pluma de un buen número de observadores (...). A finales de la década de 1810 "derecha" y "ultras" se confunden de manera casi indistinta». Tort, 2013, p. 29. 
legitimidad no era otro, en el fondo, que el de la forma de gobierno más adecuada para el régimen social surgido de la experiencia revolucionaria. Había que diseñar un trono que se adecuase a las nuevas circunstancias y, lo que era más difícil, enseñar a los antiguos monárquicos a desenvolverse en el fárrago de la nueva maquinaria constitucional.

El final del siglo XVIII había visto muchos cambios sociales que hacían inviables las formas políticas que habían dado gloria a la Francia de Luis XIV. Con una velocidad vertiginosa los modos de ser propios del Renacimiento francés se habían trastocado. La sociedad rural, vinculada a la tierra, había visto aparecer una nueva clase social enriquecida con la actividad industrial y las manufacturas. Balzac, Víctor Hugo, Stendhal, etc., se harán cargo de estos problemas, ya sea para satirizar al viejo noble decadente, criticar al burgués emergente o culpabilizar a liberales o conservadores del malestar reinante. Un cambio social de tal magnitud generó un gran malestar cultural, una sensación de pérdida de suelo firme que dio lugar al Romanticismo y a los estertores de la Modernidad. La pintura, la música, la literatura y la alta cultura en general reaccionaron pronto a estos movimientos de fondo, pero es sabido que la política es siempre la última en acusar los cambios.

Chateaubriand fue de los primeros entre sus contemporáneos en percibir la necesidad de una renovación de las viejas formas políticas, lo que le convierte, a nuestros ojos, también en un genio de la política y no solo de la literatura. La batalla política del autor de la Monarquía según la Carta fue la de defender un trono constitucional, lo cual era, en opinión de sus contemporáneos monárquicos, una contradictio in terminis, pues el constitucionalismo, al menos como lo entendían en su origen, era una forma democrática y, por tanto, revolucionaria. ¿Cabía entonces asociar ambas formas políticas, monarquía y parlamentarismo? Esta fue la propuesta de Chateaubriand y la entrada de Francia en la modernidad política.

\section{El modelo monárquico absolutista}

El modelo de monarquía propio del antiguo régimen seguía siendo operativo entre la oposición monárquica de la que formaba parte el grupo de amigos de Chateaubriand.

Durante al menos dos siglos la monarquía francesa había ido constituyendo una organización territorial y política en torno a la Corona. La modernización de la administración y del territorio había centralizado en la 
corte el poder político y administrativo de toda una nación. Había que mirar a la otra ribera del Canal de la Mancha para tratar de comprender cuál debía ser el sentido de una monarquía constitucional, porque el Estado moderno francés construido por Luis XIV había concentrado todo el poder en la Corona.

Según Diez del Corral, «el absolutismo ha reunido todos los poderes en la persona del rey, se ha diluido la figura institucional de la Corona y, aunque después de la Revolución se ha querido constituir una monarquía moderada, se ha comenzado por sentar de una manera solemne y formal el principio monárquico» ${ }^{4}$. ¿Qué era el «principio monárquico»? La concentración de poderes en la persona del rey. Por tanto, la construcción de un sistema constitucional en Francia debería ser de hecho una limitación de poderes del soberano y no la construcción de un poder orgánico. Como señala Dawson, «La estructura típica del absolutismo francés no admite adiciones ni alteraciones. El centro de todo el sistema está en la persona del monarca; y si al rey le falta la voluntad o el poder para gobernar, el sistema deja de funcionar» ${ }^{5}$.

Luis XIV podía ser tomado "como ejemplo de rey capaz de gobernar "solo" o "por sí solo". Se sabe que el propio monarca francés reivindicó esta capacidad como su mayor innovación a la muerte de Mazarino, haciendo de ella un uso que se podría calificar de propagandístico [...] Incluso llegó a vanagloriarse de servir como modelo para otros príncipes, como Felipe $\mathrm{IV} \gg^{6}$. Es conocida la anécdota que se cuenta de la entrevista entre el arzobispo de Rouen y Luis XIV el día después de la muerte de Mazarino en 1661 según la cual el clérigo preguntó: ¿A quién quiere Su Majestad que me dirija en el futuro? A lo que el joven rey respondió - A mí, monseñor, a mí mismo. «Esta declaración - según Luçay - marca la llegada definitiva del sistema gubernamental que ha regido en Francia hasta 1789. La antigua monarquía moderada terminaba de sucumbir bajo los rudos ataques de Richelieu y Mazarino confirmó su derrota ${ }^{7}$.

Cuando Chateaubriand hablaba de una Cámara de los Pares, cuando se refería a la vieja aristocracia de Francia, y cuando hablaba del honor de los pares de Francia, lo hacía en un sentido retórico dirigiéndose en realidad a los que proponían una vuelta al Estado absolutista previo a

${ }^{4}$ Diez del Corral, 1998, p. 193.

5 Dawson, 2015, p. 91.

6 Dubet, 2007 pp 216 y 217.

7 Luçay, 1976, p. 76. 
la Revolución. Según Olivier Tort «la quimera de una vuelta a una monarquía neo-feudal inspirada en la época medieval quedaba restringida a algunos originales como Montlosier, o a eruditos como Pardessus o incluso La Bourdonnaye. En general los debates giraban mayoritariamente en torno al Antiguo Régimen o, dicho de otro modo, en torno a la Edad Moderna» ${ }^{8}$.

Haciendo alarde del dominio de las palabras y de la magia del lenguaje abogaba, en verdad, por un nuevo mecanismo de control del propio rey y de sus ministros. Era de vital importancia que el rey comprendiese que, si quería salvar la monarquía en Francia, debía asumir que no vivía en tiempos de Luis XIV ${ }^{9}$ y que tenía que ceder poder a las Cámaras, a la Alta y a la Baja, a ambas. Esta retórica era además frecuente en el editorialista ${ }^{10}$ de $\mathrm{El}$ Conservador, que se movía con cautela entre las garras de la censura, y cuando parecía estar aleccionando al bando liberal, en realidad se dirigía a sus «amigos» ${ }^{11}$. En este caso enseñaba a los franceses que el nuevo sistema constitucional no debía seguir la tradición del Estado moderno absolutista ${ }^{12}$ y que, por el contrario, debía introducir las novedades del modelo anglosajón.

\section{El modelo de una nueva monarquía constitucional}

En el lenguaje posrevolucionario aun no era un lugar común la división de poderes, ni la distinción entre el poder legislativo, ejecutivo y

8 Tort, 2013, p. 152.

9 Sirva como ejemplo el que encontramos en los memoriales de Colbert «la institución de un "Conseil Royal des Finances" presidido por el rey, un monarca que "ordenaba" personalmente los gastos y los controlaba por sí solo, examinando las cuentas cada mes con su ministro». Citado en Dubet, 2007, p. 217.

10 No es muy conocido el hecho de que el editorialista de El Conservador era el propio Chateaubriand debido a que las «Cartas de Paris», que era el nombre que recibían los editoriales, estaban firmados bajo el pseudónimo de $M r$. Z.

${ }_{11}$ Utilizamos este término porque era el que Chateaubriand gustaba usar con ironía para hablar de los miembros de su partido.

12 No es aquí el lugar para abundar en la naturaleza del Estado Moderno francés en la época de Luis XIV. Valga este juicio para resumir la novedad que supuso: «La omnipotencia, la infalibilidad del soberano asumiendo el Estado en su persona, fuente de toda justicia y de toda gracia, la obediencia entera y pasiva de los sujetos, sin distinción de orden ni rango, tales eran los principios sobre los que la monarquía se iba a sentar a partir de entonces». Luçay, 1976, p. 45. 
judicial. El rey, en parte por herencia medieval, y en parte por la propia evolución del Estado moderno, aglutinaba en su persona la iniciativa legislativa, la aprobación y veto de las leyes, el nombramiento de los miembros de las Cámaras, tanto de la Alta como de la Baja, la designación de ministros, y la capacidad de juzgar e indultar ${ }^{13}$.

El problema al que se enfrentaron Chateaubriand y sus contemporáneos fue el de asumir estos desgastes y reformas necesarios, y preguntarse si la monarquía era la mejor forma de gobierno para estas circunstancias. Pocos entendieron tan bien como Constant y Chateaubriand la necesidad de adaptar la forma política a la necesidad de los tiempos ${ }^{14}$. «No se hace una monarquía constitucional con poesía y recuerdos» ${ }^{15}$, escribía Constant, maestro político de Chateaubriand. De la misma opinión era este último, para quien «el espíritu del siglo lo ha penetrado todo, y ha entrado en las cabezas e incluso en los corazones de aquellos que se creen menos afectados» ${ }^{16}$. El espíritu del siglo o el signo de los tiempos, la realidad de cada momento y las circunstancias históricas de las que nacen las instituciones son como el hijo que nace de la madre y el árbol de la semilla. «No hay manera de aislarse y escapar del camino de Europa ${ }^{17}$, predicaba Chateaubriand en el bando reaccionario intentando introducir las modernas ideas constitucionales entre ellos. Una relación natural entre forma política y circunstancia histórica que había sido profetizada por Chateaubriand haciéndose portavoz político de las corrientes políticas más modernas.

Había que aceptar los principios de la Revolución sin los hombres de la Revolución. Acabar con las personas desleales al rey, pero aceptar los cambios sociales y políticos provocados por la convulsión política de la época jacobina y de la napoleónica. Lo primero que había que dar por bueno era que el marco teórico para afrontar tales cambios era asumir las teorías anglosajonas de la división de poderes que estaban siendo introducidas poco a poco en el país, destacadamente por Constant.

13 Cfr. Zerolo, 2009.

14 Sobre la interpretación de Chateaubriand de la historia ver Aureau, Bertrand. «Idéalisme historique et Révolution chez Chateaubriand», Bulletin de l'Association Guillaume Budé, n. . 4, 1996, pp. 336-345.

15 Constant, 1989, p. 34,

${ }^{16}$ Chateaubriand, François-Renené de, Reflexions politiques sur quelques écrits $d u$ jour et sur les intérêts de tous les Français, 1814, p. 112.

17 Ibidem. 


\section{La Carta como oportunidad histórica}

Para Chateaubriand, «la monarquía representativa conviene a un pueblo envejecido en el que la educación ha extendido, en todas las clases sociales, conocimientos aproximadamente iguales y puesto en circulación un cierto número de ideas políticas» ${ }^{18}$. Las dictaduras son más propias de sociedades inmaduras, mientras que sociedades más educadas y homogéneas pueden permitirse dar más espacio a la representación. De esta manera adelantaba la importancia que tendría en su propuesta la opinión pública, la independencia de las Cámaras y la libertad de prensa.

Luis XVIII, que era sin duda el más inteligente de los hermanos, haría esfuerzos por comprender las nuevas doctrinas constitucionalistas, aunque como se puede ver por la posición de Chateaubriand, tampoco le resultaba sencillo adaptarlas entre los suyos. Sería su hermano, futuro Carlos X, el que, por no comprender el cambio de los tiempos, propondría una regresión a las antiguas formas monárquicas de poder personal y, con ello, acabaría definitivamente con la monarquía en Francia.

Chateaubriand insistía en la oportunidad histórica ante la que se encontraban. La Restauración debía serlo solo en cierta medida y los monárquicos, les gustase o no, deberían asumir que la monarquía, tal y como fue antes de la Revolución, era imposible y se debía aceptar la fuerza de los hechos. Así arengaba a los miembros de su partido: «usemos esta Carta: si nada funciona con ella podremos afirmar entonces que el genio francés es incompatible con el gobierno representativo, pero hasta el momento no tenemos derecho a condenar aquello que nunca hemos tenido» ${ }^{19}$. Chateaubriand adelantaría ideas que más tarde le harían acercarse a las doctrinas liberales de Royer-Collard, Constant y Stäel ${ }^{20}$.

En el capítulo primero de La monarchie selon la Charte retomó su principal argumento, que en realidad era una declaración de intenciones para la monarquía que venía. Decía que, si bien Francia deseaba a su rey legítimo, había tres formas de desearlo: «1., con el Antiguo Régimen; $2 .^{\circ}$, con el despotismo y $3 .^{\circ}$, con la Carta.» Tres posiciones muy distintas

18 Chateaubriand, François-René de. «Carta de París», El Conservador, 29 de marzo de 1820, disponible en Chateaubriand, 2013, p. 304.

19 Chateaubriand, François-René de. La monarchie selon la Charte, Paris, 1816, cap. XIII, p. 14.

${ }^{20}$ Cfr. Tort, Olivier. «Chateaubriand, franc-tireur de la droite (1815-1830)», Bulletin Société Chateaubriand, 2010. 
que marcaban la línea divisoria entre los ultras, los tradicionalistas y los constitucionalistas.

La monarquía constitucional «es la única buena hoy y, más aun, la única posible y esto zanja la cuestión» ${ }^{21}$. ¿Pero a quién debía convencer de esto? No siendo posible volver al Antiguo Régimen y no pudiendo hacerse una restauración total, era necesario partir de lo existente para consolidar una monarquía acorde con las necesidades de Francia. Era importante que sus compañeros del partido ultra lo comprendiesen: «Tenemos una Carta y no podemos tener otra cosa que esta Carta» ${ }^{22}$. Hagamos todo lo posible por el bien de Francia y de los franceses con lo que tenemos, diría él, y dejemos de soñar con otras realidades ideales. «Hay que sacar lo mejor de lo que tenemos en las manos» ${ }^{23}$. Es, pues, claro, que este discurso, y su consiguiente programa, no iba dirigido a los jacobinos, sino a los monárquicos más convencidos, para aquellos cuya fidelidad a la monarquía era tal que iban más allá de lo posible y clamaban por un neofeudalismo.

\section{El Conservador como órgano de la oposición reaccionaria}

Las verdades políticas hay que someterlas al veredicto de las circunstancias y este es precisamente el valor histórico de El Conservador, pues el periódico de la Restauración fue la tribuna desde la que Chateaubriand predicó el constitucionalismo a aquellos que se mostraban más reacios a adoptarlo, como Bonald, Demaistre, Castelbajac, Fievée, o La Mennais.

El Conservador no nació de la iniciativa de Chateaubriand, sino que fue concebido por Vitrolles, a la sazón ministro de Estado y miembro del consejo privado del rey, y apoyado por Monsieur, hermano de Luis XVIII, futuro Carlos X, opositor al régimen y abanderado del sector más reaccionario ${ }^{24}$. Solo más tarde se contó con Chateaubriand como redactor del periódico, y pensando más en su prestigio que en sus ideas.

El periódico fue ideado como reacción a las tendencias liberales, o «democráticas» como alegaban algunos, del régimen de la Restauración, y como foro para los ultras, donde las doctrinas constitucionales eran reci-

\footnotetext{
${ }^{21}$ La monarchie selon la Charte, op. cit., p. 1.

22 Ibidem.

${ }^{23}$ Réflexions politiques, op . cit., p. 123.

${ }^{24}$ Reboul, 1973, p. 86.
} 
bidas con recelo y, en casos como el de Bonald, con desdén. El porqué del consentimiento a ser la cara visible de esta empresa secreta sigue siendo hoy lugar de especulaciones que no han de ser valoradas aquí.

Chateaubriand hizo un fervoroso alegato a favor de la monarquía constitucional desde el fin de la Revolución, pero durante los primeros años de la Restauración se vio obligado a educar a sus «amigos», como gustaba decir con ironía ${ }^{25}$, en los principios constitucionales. Su lucha se centró en dos aspectos. El primero, afirmar que la oposición monárquica debía moverse dentro del marco constitucional establecido por la Carta demostrando que esto tenía ventajas que no había que menospreciar y, segundo, intentar unificar a todos los miembros de la oposición en un solo grupo, atrayendo hacia los moderados a muchos de los reaccionarios, «ultras» o «exclusivos» que se movían fuera del sistema y en la órbita de El Conservador.

Él mismo recapitularía su obra unos años después del siguiente modo:

Cuando la restauración vino a salvarnos, los hombres llamados al poder vieron que el restablecimiento del trono había despertado en nuestros corazones ese amor innato de los franceses hacia los hijos de San Luis: se apresuraron a aprovecharse de ese sentimiento para escapar a las trabas de la Carta. En lugar de permanecer en su puesto ante el rey, se pusieron detrás, a fin de cubrir la responsabilidad de los ministros con la inviolabilidad del Monarca ( sic.). Así atrincherados, se vanagloriaban de dirigir la nueva monarquía con las máximas de la antigua. De ahí el combate que surgió entre el ministerio y las Cámaras: el ministerio se explicaba en un tono absoluto, esforzándose en llevar la lucha a lo alto en el sagrado nombre del rey; las Cámaras, reclamando la libertad de opinión, y queriendo constreñir al ministerio en los principios. ${ }^{26}$

La Carta había establecido un poder neutral del rey, lo cual significaba que le reconocía un poder para moderar, pero también que debía permanecer al margen de las disputas políticas. La oportunidad era doble, como también lo era el peligro, y Chateaubriand tenía que moverse den-

25 Sobre la ironía del autor recomendamos Thelia, Michel, «L’ironie et Chateaubriand journaliste», Cahiers de l'AIEF , n. ${ }^{\circ} 38,1986$, pp. 63-75.

${ }^{26}$ Chateaubriand, François-René. «Carta exponiendo los principios según los cuales debe ser redactado El Conservador», El Conservador, 5 de octubre de 1818, disponible en Chateaubriand, 2013, p. 17. 
tro de un equilibro difícil. Los ultras se inclinaban hacia el absolutismo, mientras que los ministeriales lo hacían hacia la dictadura. El papel moderador del rey y la libertad de opinión fueron dos de los baluartes ideológicos para salvaguardar una libertad política de la que fue un verdadero defensor.

En la carta fundacional del periódico El Conservador, publicada el 5 de octubre de 1818, expresó como principio que la monarquía debía abandonar la forma absolutista: "pensamos que la fuerza de los realistas está en la franca adopción de la monarquía representativa» ${ }^{27}$. No obstante, al tiempo que expresó ante el partido monárquico que esta era la única forma de gobierno posible para Francia, también les advirtió de que rechazaría cualquier abuso que fuese en contra de este. «No combatiremos contra los hombres - escribía - sino contra las doctrinas y alabaremos lo que sea alabable. Si los ministros demuestran habilidad, talento y sabiduría, aplaudiremos» ${ }^{28}$.

Para evitar abusos era necesario establecer unos mecanismos de control que no podían recaer exclusivamente en el poder moderador del rey. ¿Qué sucedía con la responsabilidad de los ministros? Esta era una cuestión acuciante que estaba sin detallar en la Carta de 1814. La opinión de Chateaubriand era que «si un ministerio responsable, escondiéndose tras la inviolabilidad real, pudiese hacer todo lo que quisiese sin la moderación pública iría muy lejos» ${ }^{29}$. Era imprescindible establecer la libertad de prensa, tema que fue verdaderamente el caballo de batalla del político francés, pues, afirmaba, «no negamos a los ministros la facultad de aplicar la ley, de hacer reglamentos y ordenanzas, pero indudablemente, en un gobierno de la naturaleza del nuestro, tenemos el derecho de control y de investigación ${ }^{30}$.

\section{La lucha contra el abuso del poder ministerial}

La cuestión sobre el poder ministerial ocupó gran parte de la atención de Chateaubriand durante aquel periodo y, prueba de ello, es que el tema apareció de forma directa o indirecta en más de veinte de sus contribucio-

\footnotetext{
27 Ibidem, p. 5.

28 Ibidem.

29 Ibidem, p. 17.

${ }^{30}$ Ibidem, p. 17.
} 
nes al periódico. La razón por la que este tema era de vital importancia en el diseño de la nueva monarquía estriba en que el poder ministerial fue diseñado como punto de unión entre la vieja Francia y la nueva.

Tradicionalmente la vieja nobleza había estado ligada a la monarquía, y ambas representaban a Francia en su totalidad. La Revolución cortó este vínculo y la Restauración legalizó los derechos adquiridos de la burguesía y de una clase social emergente durante el Imperio. El lema de Luis XVIII Union et Oublie (unión y olvido) mostraba que la intención de la Carta era unir en la persona del rey a una burguesía y una nobleza enfrentadas, a las dos Francias nacidas del conflicto revolucionario. Doctrinalmente la cuestión se resolvía con el poder ministerial como mediador neutral, pero en la práctica esto exigía que la nobleza aceptase quedar apartada de la monarquía y entrar en el juego parlamentario, sometiéndose a las elecciones y al nuevo equilibrio de poderes. Algunos pensaban que esto era excesivo, porque no sólo debían olvidar los agravios sufridos durante la Revolución y el exilio, sino que además debían renunciar a su poder histórico. Convencer a la vieja aristocracia de la conveniencia de esto fue la tarea de Chateaubriand, al mismo tiempo que debía evitar que el poder ministerial cayese en el extremo de la dictadura y el abandono de la tradición.

\section{La oposición al gobierno Decazes ${ }^{31}$}

La lucha de Chateaubriand contra el bando liberal ${ }^{32}$ seguía siendo enconada en 1818 y así lo mostraba en un artículo de opinión publicado en El Conservador titulado «Sobre el estado interior de Francia» ${ }^{33}$. Allí hizo un resumen del recorrido de la monarquía en Francia desde la llegada de Luis XVIII. «Desaparecido Bonaparte, de su tiranía permanecen unas instituciones fuertes y un pueblo obediente» ${ }^{34}$, explicaba el articulista pretendiendo con ello señalar dos asuntos importantes.

31 Hemos optado por este modo de escribir el apellido del Conde de Cazes, que aparece indistintamente como «De Cazes», «de Cazes» o «Decazes» por aparecer así en los textos contemporáneos y por ser más legible en nuestro idioma.

32 «Liberal» en el lenguaje de la Restauración era sinónimo de revolucionario. Todavía no había adquirido la connotación que tiene hoy. Ver Fernández Sebastián, Javier. «Liberales y liberalismo España, 1810-1850», REP, n. ${ }^{\circ}$ 144, 2006.

33 Chateaubriand, François-René de. «Sobre el estado interior de Francia», El Conservador, 15 de octubre de 1818, disponible en Chateaubriand, 2013.

34 Ibidem, p. 28. 
El primero, dirigido a los reaccionarios, insistía en que Bonaparte había pasado por la historia de Francia, que los Cien Días no habían sido en vano y que, por tanto, no se podía volver a un estado de las cosas anterior a la Revolución y a Bonaparte como si nada hubiese pasado ${ }^{35}$. Era el argumento de hecho, contra el argumento de derecho que esgrimían los ultramonárquicos. La monarquía debía adaptarse al nuevo estado de cosas: «Con estos dos elementos podríamos crear cualquier cosa - decía, refiriéndose a un Estado fortalecido y a un pueblo dócil- desde la libertad a la esclavitud. Si vemos el peso de la segunda, recordaremos las desgracias que costó la primera, y quizás deseásemos más el fin de la opresión que la libertad» ${ }^{36}$.

El segundo, dirigido contra los ministeriales, reconoce a Luis XVIII el mérito de haber dotado a Francia de un gobierno constitucional cuando podría haber optado libremente por un gobierno despótico: «la magnanimidad de Luis XVIII prefiere romper nuestras cadenas que consagrarlas» ${ }^{37}$. Lo dice, como advierte Smethurst, para criticar «con una ironía mordaz la conducta del gobierno dominado por Decazes» ${ }^{38}$, a quien reconvenía una y otra vez por apoyarse en el ministerio para adoptar actitudes dictatoriales. Recordaba a los miembros de su partido que había que respetar el juego establecido en la Carta, que «el rey, restituido en su trono, delegó la administración de su poder» ${ }^{39}$ y que los ministros no debían abusar del mismo.

\section{Deriva dictatorial del ministerio}

En el enfrentamiento con Decazes, ministro de la policía y antiguo hombre del Imperio, es donde quizás se aprecie con mayor claridad la firmeza y la originalidad de la doctrina de Chateaubriand. Cualquier duda sobre la sinceridad de las palabras del autor de La monarquía según la

35 «Todo era posible entonces salvo la restauración del antiguo régimen, cuyos elementos ya no existían». Sobre esta idea insiste en casi todos sus escritos políticos, recordado a sus compañeros de partido que una vuelta al absolutismo es imposible porque han cambiado las ideas, las personas y las instituciones. Ibidem, p. 28.

36 Ibidem, p. 28.

37 Ibidem, p. 29.

38 Smethurst, 2016, p. 119.

39 Chateaubriand, François-René de. «Sobre el estado interior de Francia», El Conservador, 15 de octubre de 1818, disponible en Chateaubriand, 2013, p. 29. 
Carta podría despejarse siguiendo este enfrentamiento en el que no solo corría el riesgo de entrar en las listas policiales de «hombres sediciosos», sino que también arriesgaba su relación con Luis XVIII, pues no era sencillo distinguir las críticas dirigidas contra su ministro de aquellas dirigidas contra su propia persona.

La situación concreta del partido monárquico en el otoño de 1818 no era demasiado mala pues contaban con la mayoría en ambas cámaras y dominaban el juego parlamentario. Siendo esto así, ¿por qué entonces Chateaubriand abría su participación en El Conservador con estas palabras: «Teniendo, pues, que soportar los asaltos ministeriales y los ataques de los independientes, la opinión realista, que no puede responder, está miserablemente oprimida ${ }^{40}$ ? ¿Era una exageración, una licencia literaria o un juicio real? El hecho cierto es que la realidad política todavía tenía lugar fuera de las instituciones parlamentarias. Tanto Decazes como el rey eran hombres educados en la lógica natural del poder, condicionada por el conflicto de intereses y las negociaciones entre particulares, y poco sensibles a los nuevos principios de gobierno. Para Decazes, en el fondo, el parlamentarismo era un decorado de fondo para que los verdaderos actores políticos pudiesen actuar. El consejo del rey y la administración eran los focos de la decisión política, uno heredero del Antiguo Régimen, el otro del Consulado y el Imperio, pero ninguno se hacía cargo de la novedad constitucional establecida en la Carta. Por esta razón Chateaubriand centró su crítica contra el ministerio e insistió constantemente en la defensa de un sistema por encima de las personas que lo administraban:

No combatiremos en absoluto contra los hombres, sino contra las doctrinas y alabaremos lo que sea alabable. Si los ministros demuestran habilidad, talento y sabiduría, aplaudiremos; si los independientes defienden los verdaderos principios de la libertad, elogiaremos sus esfuerzos. ${ }^{41}$

Pero por desgracia ni los ministros ni los independientes parecían mostrar ese afecto por el nuevo sistema. Los ministros no entraban en el juego parlamentario y sus modos dictatoriales eran notablemente visibles.

${ }^{40}$ Chateaubriand, François-René de. «Carta exponiendo los principios según los cuales debe ser redactado El Conservador», El Conservador, 5 de octubre de 1818, disponible en Chateaubriand, 2013, p. 4.

41 Ibidem, p. 5. 
El control de la prensa, los métodos policiales del ministro de policía, y la manipulación de las cámaras a través de las leyes electorales, provocaban la reacción constante de Chateaubriand. Y los independientes tenían también muy claro su programa contra los monárquicos: defensa contra los aliados internacionales del rey, ataque al poder de la Iglesia, intervención en la ley electoral, consolidación de los bienes nacionales y la garantía de los nuevos cargos nacidos de la Revolución y del Imperio. En este contexto es en el que cobran verdadero sentido las palabras que escribió a finales de 1818, durante los últimos meses del gobierno Decazes, dirigidas a los ministeriales y a los independientes:

Queremos la Carta. Pensamos que la fuerza de los realistas está en la franca adopción de la monarquía representativa. Sus enemigos lo saben bien y sólo les temen sobre este terreno: ¡ved lo que hacen para expulsarlos! Hemos tomado la Carta como un abrigo - dicen ellos-, pero en el fondo del corazón hemos jurado la pérdida de la libertad, el restablecimiento del antiguo régimen, la vuelta de los privilegiados, la inquisición y el feudalismo. ${ }^{42}$

Nunca dejó de defender, ante sus aliados, y frente a sus adversarios, que el trono debía ser un poder neutral, que los ministros debían ser responsables y que el único modo eficaz de control del poder ministerial era la opinión pública y la garantía de la libertad de prensa. Su reproche fue que el poder ejecutivo no podía ir en contra de la opinión pública, que los ministros no podían abusar de su poder para influir en las Cámaras legislativas y en la prensa. En este mismo sentido Clément piensa que "Chateaubriand reprocha a Decazes, antiguo magistrado imperial, seguir siendo un hombre del Imperio al servicio del rey, en perjuicio de las libertades concedidas por la Carta, y de someter a Francia a una dictadura $\gg^{43}$.

\section{Distanciamiento con los ultras}

La situación política se fue recrudeciendo durante el otoño de 1818. Ante los rumores interesados de una posible insurrección de la oposición liberal aumentó la presión policial contra los periódicos y contra la opi-

\footnotetext{
42 Ibidem, p. 5.

43 Clément, 1996, p. 308
} 
nión. Decazes, como ministro de la policía, restringía las libertades establecidas en la Carta y se veía acosado en un estrecho espacio neutro entre los liberales y los monárquicos. La estrategia de mediar entre los extremos no estaba dando buen resultado y El Conservador lo aprovechó estratégicamente. La ley electoral, que de hecho era un instrumento de control tan eficaz como la censura, fue el caballo de Troya con el que Chateaubriand asaltó el poder del ministerio Decazes.

El 30 de octubre, cuando la debilidad del ministro ya era perceptible, escribió «Consideraciones sobre las elecciones». La intención de este artículo era muy clara: señalar al favorito del rey como culpable de poner en peligro el trono. Si el resultado de las elecciones había caído favorablemente del lado de los independientes era por culpa de la ley electoral: «Dijimos en el último El Conservador ${ }^{44}$ que todo árbol daba sus frutos y así la ley democrática sobre las elecciones produce una opinión democrática, primera razón ${ }^{45}$. Entiéndase aquí democrática por revolucionaria y se comprenderá la gravedad de la acusación. Se estaba atribuyendo al propio Decazes la culpa de una posible caída de la monarquía y de alentar los movimientos sediciosos. Pero a continuación Chateaubriand añadía un segundo argumento que parecía dirigido también contra el ministerio: «Los realistas, hastiados de ser perseguidos y rechazados, se han mostrado en pequeño número en los colegios electorales, segunda razón ${ }^{46}$. ¿Hastiados y perseguidos? En cierto modo era verdad, pero mucho más justo era acusar a los monárquicos de no querer entrar en el juego parlamentario. No podían lamentar el resultado de las elecciones a favor de los independientes si ellos mismos ni siquiera se habían presentado a votar. «Los realistas, no pudiendo esperar nada, han creído inútil presentarse en los colegios electorales. Yo no apruebo en absoluto - enfatiza Chateaubriand - este razonamiento: los realistas deben presentarse en sus colegios ${ }^{47}$.

En aquel momento, que coincidió con la crisis política del conde Decazes, se empezó a producir la distancia de Chateaubriand con sus «amigos». No solo se empezó a notar en la arena política la diferencia doctrinal ya conocida, sino que en las decisiones concretas las diferencias eran cada vez más visibles. Por ejemplo, en el mismo artículo fue más lejos al per-

\footnotetext{
44 Publicado en la cuarta entrega del periódico, el 22 de octubre de 1818.

45 Chateaubriand, François-René de. «Consideraciones sobre las elecciones», El Conservador, 30 de octubre de 1818, disponible en Chateaubriand, 2013, p. 44.

46 Ibidem.

47 Ibidem. p. 45.
} 
mitirse sugerir a los ultras que debían estrechar lazos con el gobierno Richelieu y atreverse a abandonar su pureza para implicarse en el gobierno de las cosas por despreciar también ellos los principios constitucionales de la Carta. Así, se atrevía a arengarles de este modo: «Estáis entre la llanura y el precipicio, hay que andar o caer, está en vosotros la elección» ${ }^{48}$. Aparecía aquí implícito el mejor Chateaubriand, el del compromiso político, el defensor de lo posible frente a lo ideal, el que buscaba unir en lugar de dividir, que se haría explícito en el siguiente artículo, cuando la crisis del gobierno Richelieu se precipitó con la destitución de su ministro del interior el 28 de diciembre.

En «Sobre la moral de los intereses y la de los deberes» ${ }^{49}$, un artículo brillante que en el subtítulo «o sobre el sistema ministerial considerado según sus efectos morales» llevaba toda una declaración de intenciones, acusó al ministerio de haber destruido todo fundamento social y moral (la sociedad francesa debía ser aristocrática) y al mismo tiempo, y cada vez con más fuerza, recordó el valor de los principios constitucionales a sus «amigos». El articulista se empeñó con dureza: «el sistema ministerial hacía surgir el despotismo de los principios populares, pretendía crear una realeza sin realistas y una monarquía sin bases monárquicas» ${ }^{50}$, y un poco después sentenciaba así: «esta moral del interés, que quieren convertir en la base de nuestro gobierno, ha corrompido más al pueblo en tres años que la revolución entera en un cuarto de siglo» ${ }^{51}$.

Los tres años del gobierno Richelieu ${ }^{52}$ se juzgaban con dureza señalando directamente a Decazes, pero como tantas veces a lo largo de este periodo, la lectura de las intervenciones de Chateaubriand tenía un doble sentido. Si la acusación contra el ministerio se dirigía a la interpretación interesada que hacían del sistema, de la ley electoral, de los nombramientos de los cargos y de la censura, esto también iba dirigido hacia sus «amigos». El gobierno representativo no debía estar ligado a los intereses de nadie. Los monárquicos también debían adherirse sinceramente a la Carta y comprender las ventajas que esta ofrecía.

48 Ibidem, p. 51.

49 Publicado el 3 de diciembre de 1818.

50 Chateaubriand, François-René de. «Sobre la moral de los intereses y la de los deberes», El Conservador, 3 de diciembre de 1818, disponible en Chateaubriand, 2013, p. 54.

51 Ibidem.

52 El gobierno de Richelieu se prolongó del 26 de septiembre de 1815 al 29 de diciembre de 1818 . 
Como señala Reboul, en aquel preciso momento «se observará también que no se trataba tanto, para Chateaubriand, de convencer a sus adversarios de la pureza de sus intenciones como de convencer a sus propios amigos de la excelencia del sistema $»^{53}$. En efecto, la ruptura entre el presidente del consejo de ministros y el ministro del interior ya era pública en noviembre de 1818, y se suponía que el gobierno caería pronto. Richelieu, que no se fiaba de los informes de Decazes que hablaban de conspiraciones ultramonárquicas, intentó una aproximación con los monárquicos que hoy podemos juzgar de desesperada. El 12 de noviembre hizo tantear la opinión del partido monárquico, el 17 y el 18 se iniciaron las negociaciones, el 25 hizo una propuesta y el 29 se intentó una renovación completa del ministerio, pero la inestabilidad era demasiado grande. Decazes dimitió y el 29 de diciembre comenzaba el gobierno Dessolles.

\section{La soledad de Chateaubriand}

¿Cuál fue la actitud de Chateaubriand ante el aparente éxito de la oposición? Sabemos que no compartió el entusiasmo de Bonald o de Fiévée, los verdaderos representantes del partido ultra, y que se prestó a escuchar al duque de Richelieu. Adoptó una posición intermedia tratando de atraer a los ultras hacia la participación en el gobierno constitucional y de rescatar a los independientes afines a la monarquía, en un intento desinteresado de unir «a los franceses», es decir, a la sociedad política, en torno a una monarquía constitucional. A partir de aquel momento, con la caída del gobierno Richelieu y el giro a la derecha de la política doméstica, es cuando se empezó a ver a un Chateaubriand más aislado y, paradójicamente, más claro en sus principios constitucionales.

Sus diferencias doctrinales con La Mennais, Bonald o Fiévée eran grandes. Mientras ellos tomaban la política desde los grandes principios e interpretan los acontecimientos como el triunfo de la Francia aristocrática sobre la democrática, Chateaubriand entendía que había un problema de hecho y que las dos Francias ya convivían desde hacía tiempo, siendo el gobierno representativo la única manera de conciliar realidades tan diferentes. Pero sus «amigos» entendían que la política se deducía de verdades eternas que no debían negociar con la historia. Bonald, desde su apa-

53 Reboul, 1973, p. 118. 
rición en el periódico, predicó contra la Carta por considerarla una fisura en la vieja monarquía por la que entraban los vicios democráticos.

Lo más significativo de aquel momento de optimismo para los monárquicos fue el silencio de Chateaubriand ${ }^{54}$. El 3 de febrero escribió sobre literatura y, del 18 de febrero al 2 de abril, en plena discusión sobre la reforma de la ley electoral, renunció a la palabra. En ocasiones los silencios son más elocuentes que las grandes palabras y, el hecho mismo de que en un momento favorable para la opinión ultra, y delicado para el estado de la política francesa, no opinase en público, arroja algo de luz sobre sus verdaderas creencias constitucionales.

Los primeros meses de 1819 estuvieron marcados por una proposición de ley realizada por Barthelemy para reformar la ley electoral. En una sociedad dividida entre la aristocracia y la burguesía, este tema era siempre delicado pues no se discutía solo acerca de una cuestión técnica, sino del modelo de sociedad que se quería para Francia. Se trataba una vez más del permanente conflicto típico de la Restauración francesa entre la sociedad monárquica y la democrática, la prerrevolucionaria y la postrevolucionaria. ¿Por qué callaba Chateaubriand en un tema tan importante para él? ¿Por qué mantenerse en silencio en el momento más crítico de la Restauración, cuando las trincheras entre la aristocracia y la burguesía estaban más definidas y la batalla era más encarnizada? La respuesta a este silencio es quizás uno de los puntos más difíciles de explicar de la biografía política de Chateaubriand.

Partiendo de un hecho cierto quizás podamos llegar a plantear una hipótesis. En primer lugar, hoy ya no es discutible que Chateaubriand solo era la fachada de un complejo entramado de personajes influyentes detrás de los que al final se encontraba Monsieur, futuro Carlos X y jefe de la oposición ultra. Queda descartado cualquier vínculo con sociedades secretas como Les chevaliers de l'anneau, cuya posible relación solo aparece en las calumnias vertidas por los folletos liberales y de los que, como hemos señalado, se quiso hacer eco Decazes para combatir a los monárquicos. Por tanto, si lo cierto es que Chateaubriand solo era la firma conocida de un periódico que servía a la oposición, su silencio, según la hipótesis más plausible, es que la dirección del periódico le pidiese callar para dar voz a opiniones más beligerantes como la de Bonald, reconocido

${ }^{54}$ El 3 de febrero escribió «Sobre los anales de literatura» y el 18 de marzo «Acerca de una obra del conde Boissy-d'Anglas». 
anticonstitucionalista y ferviente ultramonárquico. Y si consideramos importante detenernos en este aspecto aparentemente especulativo es porque precisamente subraya el carácter auténtico y original de la propuesta política de Chateaubriand para la monarquía posrevolucionaria.

El silencio de la principal firma de El Conservador en pleno debate de la propuesta de reforma de la ley electoral de Barthélemy que exacerbó aún más la tensión entre los liberales y los monárquicos explicita que Chateaubriand se encontraba en una posición intermedia, ideológicamente más próximo a los liberales en lo que a sus ideas constitucionales se refiere, y afectivamente más cerca de los monárquicos. La monarquía constitucional era la mejor intermediación en un conflicto social sin aparente solución, un equilibrio difícil en una época de transición.

\section{Último sermón constitucional en la parroquia monárquica}

Después del dilatado silencio durante el invierno de 1819, Chateaubriand reapareció para dar el que quizás fuese su último combate entre las filas de los ultras. Lo hizo con contundencia:

No se puede depositar ninguna esperanza en la nueva administración. Hemos demostrado un raro instinto de mediocridad: si en los últimos rangos del imperio, con Bonaparte, existían algunos genios secundarios de los cuales no habíamos oído apenas hablar, hemos ido precisamente allí a buscar a los grandes hombres para la monarquía legítima. ${ }^{55}$

La nueva administración, en manos de Dessolles ${ }^{56}$, era más favorable a la mayoría monárquica y la redacción de El Conservador debía resolver las grandes cuestiones doctrinales, y no solo estratégicas, que tenía pendientes. Los ultras debían decidir si querían participar en un gobierno del que formase parte Decazes como ministro del interior, si podían poner condiciones a esa posible participación y, lo que era más importante desde un punto de vista formal, si la defensa de las libertades constitucionales, en particular la de prensa, eran irrenunciables.

55 Chateaubriand, François-René de. «Política», El Conservador, 2 de abril de 1819, disponible en Chateaubriand, 2013, p. 98.

5629 de diciembre de 1818-19 de noviembre de 1819 . 
Ante la perspectiva de una inminente sucesión de Luis XVIII ${ }^{57}$ los monárquicos se postulaban para ocupar el poder tras la estela del futuro Carlos X, pero como es sabido, es más sencillo que los diferentes intereses se mantegan unidos en la oposición que en el poder.

La expectativa de abandonar por fin la oposición empezó a dividir al frente monárquico y, en este contexto, el recorrido doctrinal que hizo Chateaubriand en el citado artículo tenía la intención de señalar los puntos comunes que no debían abandonarse y que podrían resumirse en uno solo: sin apoyo a los principios constitucionales establecidos en la Carta la monarquía no se sostendría.

«¿Dónde vamos?», se preguntaba retóricamente en lo que en realidad era una increpación a los suyos. «Nuestras instituciones, aparentemente de pie, están caídas» ${ }^{58}$. Desde la disolución de la Cámara introuvable, y la manipulación de la composición de las Cámaras a través de la ley electoral, hasta la ley Barthelemy que entonces se discutía, y que alteraba la composición de las cámaras en el sentido contrario, todo habían sido desprecios, según Chateaubriand, de las instituciones parlamentarias. Ni los liberales ni los monárquicos terminaban de tomarse en serio el nuevo sistema.

En «Política» repasó los agravios infligidos al sistema en lo que, en verdad, era un último intento programático de salvar a la monarquía constitucional de la deriva errática hacia la que la conducían entonces los monárquicos.

Empezó por la cúspide del sistema, el principio sobre el que tanto había insistido en La monarquía según la Carta, que debía ser la responsabilidad de los ministros y su sometimiento al control parlamentario. Se lamentaba de que no fuese así y de que, en un principio Decazes, y luego los monárquicos, se sirviesen de ese poder dictatorial para sus propios intereses:

Hoy se debate sobre la responsabilidad de los ministros, ¿pero existe una responsabilidad tal cuando veinte, treinta, cuarenta, cincuenta, se-

57 En el Journal du Commerce de 28 de febrero de 1819 aparecía el siguiente comentario que no estaba muy lejos de la realidad: «Los ultrarealistas depositaban sus esperanzas en la enfermedad del rey (...). Su restablecimiento les contraría porque en su delirio parecen contar con un cambio del sistema de gobierno». Citado en Reboul, 1973, p. 159.

58 Chateaubriand, François-René de. «Política», El Conservador, 2 de abril de 1819, disponible en Chateaubriand, 2013, p. 98. 
senta pares, parientes o amigos de los ministros, pueden ser introducidos de repente en la Cámara alta (...) No obstante, la monarquía representativa gira sobre la responsabilidad ministerial: quítese esta responsabilidad y no quedará nada. ${ }^{59}$

Volvía en este artículo sobre las ideas vertidas en uno de sus más brillantes artículos «Sobre la moral de los intereses»y, en este como en aquel, la intención era doble. Recordar a los liberales y a los ultras que la utilización del sistema representativo en su propio interés era perjudicial para el partido, para la monarquía, y para Francia. La única prevención de esta utilización interesada del sistema era la interposición de una serie de frenos y controles que había que respetar, principalmente dos: la responsabilidad de los ministros y la libertad de prensa.

Sobre la libertad de prensa, en aquel desesperado intento de abril de 1819 por convencer a los suyos de las bondades del sistema establecido en la Carta, también se pronunció, y con claridad. Una de las preguntas que estaban sobre la mesa de los ultras era si el control de la prensa era justificable para contener las amenazas revolucionarias y detener la sombra de Napoleón que todavía era muy alargada. La mayoría de sus amigos eran partidarios de la censura, y Chateaubriand se encontraba muy solo en la defensa de la libertad de prensa. Así, clamaba: «Se aporta una ley sobre la libertad de prensa: nueva burla. ¿Dónde se encuentra esta libertad de ley? $\gg^{60}$. Se permitía secuestrar una edición sin resolución judicial; se exigía el depósito de cada edición previo a la publicación, incluso diaria, en el ministerio; estaban prohibidas las crónicas parlamentarias y se exigía la publicación de los comunicados oficiales; se prohibían los «ultrajes a la moral pública o a las buenas costumbres» que daban carta blanca a la censura; y los tribunales que se pronunciaban sobre la prensa estaban designados por los ministros, con lo que el control lo ejercía el ejecutivo sobre la prensa, y no al contrario como establecía el diseño constitucional de la Carta. De ahí que Chateaubriand se pronunciase con una contundencia desacostumbrada: «Todo, en nuestras nuevas leyes, destruye la monarquía constitucional» ${ }^{61}$. Y entiéndase aquí el contexto que señalábamos para ver a quién iban dirigidas estas duras palabras porque, a nuestro juicio, en esto reside el interés de esta investigación y del pensamiento político del
59 Ibidem.
${ }^{60}$ Ibidem.
61 Ibidem. 
polígrafo francés. Las nuevas leyes que aprobaba la mayoría conservadora iban encaminadas a la destrucción de la monarquía constitucional y a la añorada vuelta por tantos ultras al antiguo régimen, si es que tal cosa era posible en una sociedad francesa dividida entre liberales y monárquicos.

La visión de Chateaubriand era profundamente crítica y concluía el artículo dejando poco lugar a la esperanza: «Hemos introducido mil gérmenes de destrucción en el Estado, y el Estado está amenazado de muerte» ${ }^{62}$. No se podía salvar a la monarquía con los viejos principios y actitudes prerrevolucionarias. Lo que era criticable en los liberales lo era también en los monárquicos y así, con la fina ironía que le caracteriza, terminaba recordando las palabras del príncipe de Talmont, monárquico que murió en la guerra de la Vendée: «los jacobinos cumplen con su oficio, los realistas con su deber» ${ }^{63}$ o, lo que era lo mismo, acusó a los suyos de no estar a la altura de sus obligaciones.

\section{El canto del cisne: la libertad de prensa}

El otoño de 1819, con la convalecencia de Luis XVIII y el partido ultra agazapado a la espera del salto al poder con el advenimiento del futuro Carlos X, fue de nuevo el del silencio de Chateaubriand en las cuestiones más sensibles para el régimen. Prueba de ello es que sus publicaciones fueron sobre un viaje a Jerusalén, sobre los misioneros del Mont Valerien, sobre la Universidad, uno sobre la Vendée que pasaría a los anales del periodismo, o sobre literatura. Ya sabemos que cuando se retiraba a las alturas de la literatura, la historia o la teología era porque no encontraba lugar en la política. Esta razón explicó los retiros, las ausencias y los silencios de Chateaubriand.

En mitad de este dilatado silencio encontramos un artículo sobre la libertad de prensa publicado el 8 de octubre de 1819. Es significativo que el último artículo firmado sin pseudónimo sobre un tema controvertido fuese sobre la libertad de prensa. Nos ayuda a hacernos idea de lo querida que fue para Chateaubriand esta libertad el hecho de que decidiese hablar de ella cuando ya apenas tenía voz entre los suyos, y cuando estaba seguro de que la deriva absolutista que tomaban los monárquicos era irreversible.

\footnotetext{
62 Ibidem.

${ }^{63}$ Ibidem, p. 106.
} 
Su testamento político, en este sentido, el legado que quiso dejar a los hijos de la Restauración fue el de la libertad de prensa.

Chateaubriand insistió en este principio como algo fundamental del nuevo régimen desde la llegada al trono de Luis XVIII: «es necesaria esta libertad o la constitución no es más que un juego» ${ }^{64}$. Y así lo reiteró en numerosas ocasiones, de forma más o menos contundente: «si se desea quemar la Carta, nada más consecuente que suprimir la libertad de prensa, pero si se pretende conservar una suprimiendo la otra, entonces es un absurdo» ${ }^{65}$. Y es precisamente en este punto donde podemos encontrar la aportación más original y personal del genio normando, opinión compartida por Jaume, quien recuerda que «defendía la libertad de publicar hasta tal punto que fue recibido en Praga en 1833 como patriarca de la libertad de prensa» ${ }^{66}$.

«Para Chateaubriand - escribe Jaume - el orden constitucional se resume en la permutabilidad de la opinión y la libertad. El gobierno representativo es un diálogo permanente de la opinión consigo misma» ${ }^{67}$. Con esto quiere significar que, en efecto, la propuesta constitucional del vizconde era mucho más moderna y liberal de lo que podría pensarse, pues situaba la clave del sistema constitucional en el control del gobierno y las Cámaras por parte de la opinión, estableciendo así un poder que no se situaba en el marco tradicional anglosajón de la división del poder tripartita.

Recordemos que la Carta establecía, en el artículo 8, una regulación muy vaga que dejaba demasiado espacio a la interpretación: «los franceses tienen el derecho de publicar y de imprimir sus opiniones, siempre que sean conformes a las leyes que deben reprimir el abuso de esta libertad». El artículo estaba redactado pensando en libros y panfletos, pero no en los periódicos, que seguirían estando bajo el control de la policía. No en vano, según Belanger, «la monarquía censitaria desconfiaba mucho, como Napoléon I, de la prensa ${ }^{68}$ y la sometió a un estricto control que otorgaba al ministerio un doble mecanismo: la autorización y la censura previa. La autorización real se exigía tanto a periódicos como a escritos con cierta periodicidad; y la censura afectaba a escritos que no superasen las veinte hojas de impren-

${ }^{64}$ Chateaubriand, François-René de. La monarchie selon la Charte, op. cit., p. 17.

65 Chateaubriand, François-René de. «Sobre la libertad de prensa», El Conservador, 8 de octubre de 1819, disponible en Chateaubriand, 2013, p. 242.

66 Jaume, Lucien. 1993, p. 867.

67 Ibidem.

68 Bellanger, 1969, p. 29. 
ta $^{69}$, con la excepción de que estuviesen redactadas en una lengua muerta o que emanasen de una autoridad religiosa. A estos controles se sumaba la exigencia legal a impresores y libreros de obtener una licencia, que normalmente suponía la entrega de una enorme cantidad de dinero a modo de fianza, y a realizar un juramento. Todo este mecanismo, que se prolongó durante la Restauración sin que se llegase a hacer efectiva una apertura verdadera, estaba controlado por el ministerio de la policía que, en París, estableció un férreo control a través de la asignación de un comisario para cada periódico, que hacía dos visitas diarias y tenía una amplia potestad sancionadora que podía extenderse incluso hasta la clausura del periódico.

¿Qué podría suceder si los periódicos cayesen en manos del Ministerio? Si se podían cerrar periódicos por mostrar una u otra opinión, publicar discursos mutilados pronunciados en las Cámaras, prohibir directamente algunas publicaciones particulares contrarias a los intereses del Ministerio, destituir a censores que dejaban pasar artículos favorables al partido monárquico, era claro que no existiría una opinión pública en cuanto tal, sino una opinión creada por el poder. Por ello, «seamos consecuentes: o renunciamos al gobierno representativo o aceptamos la libertad de prensa; no hay ninguna constitución libre que pueda existir con los abusos que acabo de señalar» ${ }^{70}$. La tentación del gobierno era seguir usando absolutamente el poder sin comprender lo que había sucedido en la sociedad francesa y que la Revolución había mostrado tan claramente. «Combatiendo por la libertad de prensa, escribe Clément, Chateaubriand entendió bien que esta es el motor de un régimen liberal independientemente de las formas políticas transitorias que la amparan, y del carácter de la sociedad $\gg^{71}$.

Es en este contexto en el que debe entenderse la originalidad de Chateaubriand, pues ni había tradición de libertad de prensa en Francia, ni el texto legal de la Carta daba mucho lugar a una interpretación favorable hacia dicha libertad. «Es absolutamente imposible, contrario a todos los principios de la monarquía representativa, dejar exclusivamente la prensa en manos del Ministerio» ${ }^{72}$, decía en 1816 al ver que la prórroga al desarrollo legislativo de la Carta se posponía sine die, sin que la aclamada libertad terminase de llegar nunca.

${ }^{69}$ Equivale a 320 páginas en $8 .^{\text {a }}$.

${ }^{70}$ Chateaubriand, François-René de. La monarchie selon la Charte, op . cit., p. 17.

71 Clément, Jean Pierre. «Chateaubriand et la liberté», Société Chateaubriand, vol. n. ${ }^{\circ} 29,1986$, p. 68.

${ }^{72}$ Chateaubriand, François-René de. La monarchie selon la Charte, op. cit., p. 16. 
Chateaubriand imploraba en el otoño de 1819 a los ultras que escuchasen las voces que pedían la citada libertad pues estaba convencido de que el trono en Francia solo podía mantenerse si establecía su base en la opinión: «los realistas deben tener por cierto que todo proyecto contra la libertad de prensa les amenaza especialmente» ${ }^{73}$. Fatigado ya por una larga lucha que parecía llegar a su fin sin ningún avance favorable, Chateaubriand escribía: «el señor ministro del interior ha pedido que se le presente un informe sobre el estado de la libertad de prensa en Francia y también es cierto que la conclusión de este es poco favorable a esta libertad» ${ }^{74}$. Poco se había avanzado en este sentido y, según la opinión de Chateaubriand, se había desaprovechado una buena oportunidad para establecer una institución que habría dado estabilidad al sistema constitucional.

Llegaba ya el momento de los lamentos y reproches: los «enemigos del gobierno representativo no cesan de lamentar los tiempos felices de la arbitrariedad imperial y temen que siempre se vayan a desenterrar algunas de sus vilezas. Odian la Carta y la libertad de prensa les parece una verdadera plaga porque tarde o temprano podrá expulsarles de los asuntos políticos» ${ }^{75}$. ¿Quiénes eran esos enemigos? La censura y la presión de los ultras no permitía a Chateaubriand expresarse con la claridad que le hubiese gustado, pero podemos pensar sin temor a equivocarnos que estos últimos escritos de El Conservador, cuando todo apuntaba a su fin, iban más dirigidos a sus «amigos» que a sus enemigos ${ }^{76}$. A estos decía: «ningún gobierno constitucional sin libertad de prensa, lo hemos dicho y repetido en todos los escritos, y creemos haberlo probado» ${ }^{77}$.

Con ironía encomiaba a los ministeriales a restablecer la censura si lo que querían era acabar con el rey porque, ya lo hemos visto, o la monar-

${ }^{73}$ Chateaubriand, François-René de. «Sobre la libertad de prensa», El Conservador, 8 de octubre de 1819, disponible en Chateaubriand, 2013, p. 243.

74 Ibidem, p. 241.

75 Ibidem.

76 Tort explica cómo a partir de este momento Chateaubriand se irá aproximando cada vez a las posturas liberales. $C$ fr. «Chateaubriand et la gauche sous la Restauration: de l'hostilité au rapprochement partiel». Société Chateaubriand, vol. 53, año 2010.

77 Chateaubriand, François-René de. «Sobre la libertad de prensa», El Conservador, 8 de octubre de 1819, disponible en Chateaubriand, 2013, p. 242. Esta frase aparece literalmente también en Réflexions politiques, Monarchie selon la Charte, «Rapport sur l'état de la France (12 de mayo de 1815)» y «Opinion sur le Projet de Loi relatif à la Liberté de la Presse». 
quía constitucional respetaba la opinión pública, o dejaría de serlo: «los realistas deben tener por cierto que todo proyecto contra la libertad de prensa les amenaza especialmente ${ }^{78}$. Esta frase resume gran parte de la propuesta del político normando para una monarquía posible. En primer lugar, porque situaba a la libertad de prensa como clave de bóveda del sistema y, en segundo lugar, daba por aprendida la lección de la Revolución que había dado carpetazo al absolutismo. Chateaubriand, desde la tribuna reaccionaria, hacía una última llamada a sus amigos: «Al obtener la libertad de prensa los realistas lo tienen todo. En tanto que esta libertad subsista el triunfo está asegurado» ${ }^{79}$. Y así, en realidad, realizaba su última advertencia del peligro de la deriva dictatorial que estaba tomando el gobierno de Decazes: «los que se figuran que se puede suspender impunemente la Constitución, retorcer las palabras de la Carta para sacar de ellas la arbitrariedad, conocen muy poco la fuerza de las cosas y la capacidad de los hombres que creen dirigirnos» ${ }^{80}$.

\section{Cierre del periódico El Conservador}

La censura recibió el gran espaldarazo con el asesinato del Duque de Berry el 13 de febrero de 1820, imputado a los excesos de los liberales y de los panfletos de izquierda, que fue aprovechado para aprobar la ley de 31 de marzo de 1820, gestada por Decazes antes de su caída y propuesta por Richelieu ante una viva oposición de liberales y conservadores. El 20 de febrero de 1820 se disolvieron las Cámaras y empezó el gobierno ultrarrealista de Villèle, con el que Chateaubriand no simpatizaría en absoluto.

El magnicidio fue la justificación que la dictadura ministerial necesitaba para restaurar de facto una monarquía muy parecida a la del Antiguo Régimen y para acabar con el «experimento» constitucional. El 29 de marzo de 1820 Chateaubriand escribía, a modo de sentencia de un régimen que, en realidad, nunca llegó a existir:

seamos pues escrupulosos con el abandono de esas libertades de las que sin duda se ha abusado horriblemente, pero cuya ausencia, incluso tem-

78 Chateaubriand, François-René de. «Sobre la libertad de prensa», El Conservador, 8 de octubre de 1819, disponible en Chateaubriand, 2013, p. 243.

79 Ibidem, p. 243.

80 Ibidem, p. 247. 
poral, podría provocar el nacimiento de otra especie de mal. Cuidémonos de atacar demasiado, por nuestros espantos, a este gobierno representativo que, sin duda, tiene inconvenientes, como todos los demás, pero que es la transición natural entre las antiguas ideas y las nuevas, el punto de encuentro entre la monarquía y la república. ${ }^{81}$

Chateaubriand degustó así el premio amargo de la derrota. Durante el tiempo que pudo expresarse entre los monárquicos a través de El Conservador advirtió de que, si a los franceses se les hiciese elegir entre la libertad y la monarquía, elegirían la primera. La Revolución era un hecho y las libertades constitucionales establecidas en la Carta eran la única vía para conciliar a la vieja Francia con la nueva. Los ultras, cuando finalmente accedieron al poder con el ministerio Villèle, ignoraron estos consejos y optaron por un intento de volver al Antiguo Régimen. Los hechos dieron la razón a Chateaubriand en forma de derrota de la monarquía. Prueba de ello es que Carlos X, el promotor de El Conservador, y líder en la sombra de la oposición, solo pudo mantenerse en el trono seis años.

\section{Conclusión}

De Luis XVIII se decía que tenía cabeza pero que no tenía piernas, de su hermano Carlos X lo contrario, tenía piernas, pero no cabeza. Luis XVIII supo escuchar el signo de los tiempos y realizó el intento de adaptar la monarquía a las nuevas formas constitucionales, sirviéndose para ello del consejo e influencia de hombres de gran talla entre los que, paradójicamente, se encontraba el ultra Chateaubriand. Carlos X, sin embargo, no tenía la prudencia intelectual necesaria como para entender los equilibrios necesarios que exigían las circunstancias de la Restauración, lo que le llevó a tomar decisiones simplistas, intentar recuperar el poder absoluto y, con ello, pasar a formar parte de la lista de Borbones que no murieron sentados en el trono.

El papel de intérprete de la historia que realizó Chateaubriand empieza a ser conocido ahora a través de sus escritos políticos y esta es la razón por la que nos hemos centrado especialmente en sus intervenciones desde la tribuna ultra que le ofrecía El Conservador. La originalidad

${ }^{81}$ Chateaubriand, François-René de. «Carta de París», El Conservador, 29 de marzo de 1820, disponible en Chateaubriand, 2013, p. 320. 
y profundidad de la propuesta política de Chateaubriand se conoce mejor cuando entra en conflicto con sus supuestos amigos. Desde allí predicó la doctrina constitucional a un auditorio reaccionario y profetizó la caída de la monarquía.

Los hechos le dieron la razón con el fracaso de su proyecto político, pero hoy es innegable que sus ideas y su interpretación de la Carta acabaron por influir decisivamente en el diseño del constitucionalismo. Esto explica su aproximación progresiva a los liberales doctrinarios a partir de 1830, tras la caída del trono de Carlos X.

La libertad de prensa, el poder neutral del rey, la responsabilidad de los ministros y la separación de las Cámaras han pasado a formar parte de nuestra cultura política constitucional, y en gran parte se lo debemos a la activa presencia que tuvo Chateaubriand en el corto, pero crucial, período de1818 a1820.

\section{Bibliografía}

AUREAU, Bertrand, «Idéalisme historique et Révolution chez Chateaubriand», $B u$ lletin de l'Association Guillaume Budé, n. ${ }^{\circ}$ 4, 1996, pp. 336-345.

Bellanger, Claude et al. Histoire générale de la presse française, Presses Universitaires de France, París, 1969.

Chateaubriand, François-René de, El Conservador (1818-1820), CEPC, Madrid. 2013.

Chateaubriand, François-René de, Réflexions politiques sur quelques écrits du jour et sur les intérêts de tous les Français, Le Normant, Paris, 1814.

Chateaubriand, François-René de, La monarchie selon la Charte, Le Normant, Paris, 1816.

CLÉMENT, Jean Paul, «Chateaubriand et la liberté», Société Chateaubriand, vol. n. ${ }^{\circ} 29,1986$.

CLÉMENT, Jean Paul, Chateaubriand politique, «Introduction», Imprimerie Nationale, Paris, 1993.

CLÉMENT, Jean Paul, «À propos de la création du Conservateur (1816-1820)», Bulletin de l'Association Guillaume Budé, n. ${ }^{\circ} 4,1996$.

Constant, Benjamin, Cours de politique constitutionelle, Plancher, Paris, 1818, vol. 1 , I.

Constant, Benjamin, Escritos políticos, CEC, Madrid, 1989.

Constant, Benjamin, «Des Chambres (VII article) Projet de loi sur les Journaux», Mercure de France, 15 de febrero 1817, en Obras completas, t. X, 1, Tübingen, Niemeyer, 2001. 
DAwson, Christopher, Los dioses de la Revolución, Encuentro, Madrid, 2015.

DíEZ DEl CoRral, Luis, El liberalismo doctrinario, en OO.CC, CEPC, Madrid, 1998.

DuBET, Anne, «¿La importación de un modelo francés? Acerca de algunas reformas de la Administración española a principios del siglo XVIII». Revista de Historia Moderna, n. ${ }^{\circ}$ 25, 2007.

DURCHARDT, Heinz, El absolutismo, ¿un mito?: revisión de un concepto historiográfico clave, Idea Books, Madrid, 2000.

ElíAs, Norbert, La sociedad cortesana, FCE, Madrid, 1993.

FERnÁndez SEBASTIÁn, Javier, «Liberales y liberalismo España, 1810-1850», $R E P$, n. ${ }^{\circ} 144,2006$, p. 130.

GAllego, Elio A., Sabiduría clásica y libertad política, Ciudadela, Madrid, 2009.

JAUME, Lucien, «Chateaubriand. Grands écrits politiques», Revue Francaise de Science Politique, 1993.

LuÇAY, Helion, Les origines du pouvoir ministériel en France. Les secrétaires d'État depuis leur institution jusqu'à la mort de Louis XV. Slatkine, Ginebra, 1976.

Millán AlBA, José Antonio, «Prólogo a Memorias de ultratumba», en Memorias de ultratumba, Cátedra, Madrid, 2010.

NeGro, Dalmacio, Historia de las formas del Estado. Una introducción, El Buey Mudo, Madrid, 2010.

RoldÁN, Darío, «Historia y política. La historiografía liberal entre la Restauración y el Segundo Imperio», Revista de Instituciones, Ideas y Mercados, n. ${ }^{\circ} 57$, octubre, 2012.

Simoneti, Pascal, «Mourir comme un Bourbon: Louis XVIII, 1822», Revue d'Histoire Moderne \& Contemporaine, 1995, 42-1 pp. 91-106.

Smethurst, Colin, «Chateaubriand et la gauche du temps du Conservateur», Bulletin Société Chateaubriand, Vol.53, 2011.

SMETHURST, Colin, Écrits politiques (octobre 1818-mars 1820) «Le Conservateur», Honore Champion, Paris, 2016.

ThÉLIA, Michel, «L'ironie et Chateaubriand journaliste», Cahiers de l'AIEF, n. ${ }^{\circ} 38,1986$, pp. 63-75.

TORT, Olivier, «Chateaubriand, franc-tireur de la droite (1815-1830)», Bulletin Société Chateaubriand, 2010.

TORT, Olivier, «Chateaubriand et la gauche sous la Restauration: de 1'hostilité au rapprochement partiel». Société Chateaubriand, vol. 53, año 2010.

TorT, Olivier, La droite française. Aux origines de ses divisions (1814-1830), CTHS, Paris, 2013.

TORT, Olivier, «Le royalisme comme expression des pathologies méridionales : réflexions sur la représentation politique française à l'époque de la Restaura-

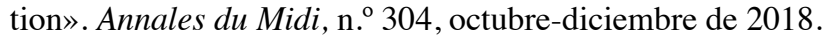


WARESQuiel, Emmanuel, «Histoire de la Restauration (1814-1830)», Perrin, Paris, 2002.

Zerolo, Armando, Los orígenes del Estado Minotauro, Sequitur, Murcia, 2009.

Zerolo, Armando, La Monarquía Constitucional. Principios del Estado Liberal según Chateaubriand, Dykinson, Madrid, 2017.

\section{Datos del autor}

Armando Zerolo Durán, profesor de la Universidad San Pablo-CEU de Filosofía Política y del Derecho. Director de la colección "Mínima Política» en Ediciones Encuentro. Ha sido Coordinador del Grado en Ciencias Políticas de la USP-CEU. Se ha especializado en las corrientes liberales de los siglos XIX y XX en España y Francia. Entre sus monografías destacan: "Génesis del Estado Minotauro. El pensamiento político de Bertrand de Jouvenel», "La Monarquía Constitucional. Principios del Estado Liberal según Chateaubriand", "Histoire de l'Europe Libérale» (VV.AA.), "Historia del Análisis Político» (VV.AA.). Ha escrito además numerosos artículos científicos, y ha sido traducido al francés, al inglés y al ruso. 